\title{
Crustal flow beneath the eastern margin of the Tibetan plateau*
}

\author{
Jieshou Zhu ${ }^{1, *}$ Junmeng Zhao ${ }^{2} \quad$ Xiaotao Jiang ${ }^{1}$ \\ Jun Fan ${ }^{3}$ and Chuntao Liang ${ }^{1}$ \\ ${ }^{1}$ Department of Geophysics, Chengdu University of Technology, Chengdu 610059, China \\ ${ }^{2}$ Institute of Tibetan Plateau Research, Chinese Academy of Sciences, Beijing 100101, China \\ ${ }^{3}$ Earthquake Administration of Sichuan Province, Chengdu 610041, China
}

\begin{abstract}
In large continental orogens, an important research topic is the behavior of deep crustal and upper mantle deformation, and the flow styles of ductile material. The morphology of the eastern margin of the Tibetan plateau, adjacent to the Sichuan basin, is characterized by very steep relief with high mountain ranges. The crust beneath this region slows the velocities in the middle and lower crust. We have adopted a relatively dense network to inverse the detailed structure of the crust and upper mantle along the eastern margin of the Tibetan plateau and Sichuan basin, using teleseismic data via receiver function analysis. The results are in-line with the hypothesis that viscous crustal material is flowing beneath the eastern margin of the Tibetan plateau and that this process drives overlying crustal material around the strong and rigid Sichuan basin. When the viscous material hits this obstruction, flows are divided into two or more branches with different directions. The upper part of the upwelling viscous flow produces the pressure to intrude the upper crust, thereby driving uplift of mountain ranges and high peaks. In contrast, the lower part of the downwelling viscous flow produces the pressure to intrude the lower crust and upper mantle to deepen the Moho discontinuity, causing observed crustal thickening.
\end{abstract}

Key words: eastern margin of the Tibetan plateau; viscous crustal flow; upwelling and downwelling; mountain range uplift; deepened Moho discontinuity

CLC number: P315.2 Document code: A

\section{Introduction}

The behavior of the crust and lithospheric mantle in large continental orogens is an important research subject of continental tectonics. The major questions are the deformation styles and flow processes of the deep crust and lithospheric mantle (Beaumont et al., 2004; Gray and Pysklywec, 2012). The Tibetan plateau is the type example of a large orogenic plateau formed as a result of continent-continent collision. The morphology of the plateau and its margins suggests that the preexisting variations of strength and viscous flow in the deep crust and lithospheric mantle have influenced the growth and shape of the plateau. The morphology

\footnotetext{
* Received 15 October 2012; accepted in revised form 12 November 2012; published 10 December 2012.

† Corresponding author. e-mail: zhujs@cdut.edu.cn

(C) The Seismological Society of China, Institute of Geophysics, China Earthquake Administration, and Springer-Verlag Berlin Heidelberg 2012
}

of the region along the eastern margin of the Tibetan plateau, adjacent to the strong rigid crustal basement of the Sichuan basin, is characterized by very steep relief with high mountain ranges and steep peaks (Clark et al., 2004; Burchfiel et al., 1995, 2008; Kirby et al., 2003).

Lower crustal flow has been proposed to occur throughout the Tibetan plateau (Shen et al., 2001; Beaumont et al., 2004; Cook and Royden, 2008; Gray and Pysklywec, 2012). High temperatures, and the presence of even small amounts of fluids or partial-melt, can greatly reduce the strength of continental crust that may have resulted from the generation of high topography. This may enable a lateral flux of material throughout the plateau with minimal deformation of the rigid upper crustal layer (Cook and Royden, 2008). A number of geophysical observation points to the presence of fluids or partial-melt in the middle or lower crust of southern Tibet (Brown et al., 1996; Nelson et al., 1996). Receiver function studies in central Tibet have 
provided evidence of crustal low velocity zones that may have formed as a result of the presence of crustal fluids (Nelson et al., 1996; Clark and Royden, 2000; Clark et al., 2005).

The crust beneath the eastern margin of the Tibetan plateau slows the $\mathrm{P}$ - and S-waves in a low velocities zone in the middle crust (Wang et al., 2007; Zhu, 2008; Liu et al., 2009). Teleseismic receiver function analysis indicates the presence of a middle crust low velocity zone extending from the thick crust of the western Sichuan basin through the thinner crust of Yunnan (Xu et al., 2007). In contrast, the Sichuan basin has been interpreted as a region with strong rigid lithosphere and low heat flow (Clark and Royden, 2000; Clark et al., 2004, 2005).

However, the formation of the crustal low velocity zone is still not clear along the eastern margin of the Tibetan plateau, and the distribution pattern and the dynamic process of viscous fluids in the middle and lower crust and upper mantle are unknown. We have adopted a relatively dense network using both temporary and permanent broadband seismometers that use passivesource data to inverse the fine velocity structure of the crust and upper mantle in the eastern margin of the Tibetan plateau and the Sichuan basin. The results of the fine velocity structure could reveal the distribution pattern of viscous fluids in the crust, and the dynamic behavior of the eastern margin of the Tibetan plateau.

\section{Morphology and crustal dynam- ics of the eastern margin of the Tibetan plateau}

The topographic expression along the eastern margin of the Tibetan plateau is irregular and diffuse (Kirby et al., 2003). The eastern margin of the Tibetan plateau adjacent to the strong rigid Sichuan basin is characterized by a series of extremely steep mountain ranges and high peaks. By contrast, the southeastern and the northeastern margins of the plateau are characterized by gentle slopes, and no significant topographic relief (Figure 1).
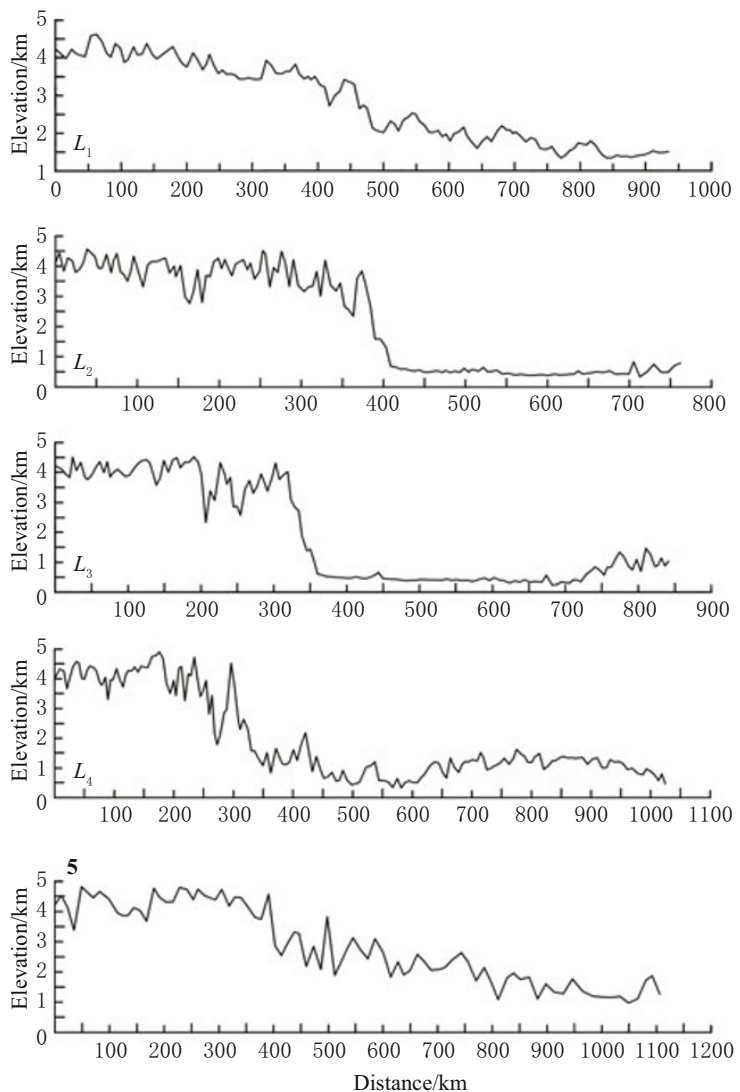

Figure 1 Morphology of the eastern margin of the Tibetan plateau and the Ordos basin, Qinling, Sichuan basin, and south Yangtze craton. (a) Location of the five profiles along the eastern margin of Tibetan plateau. The famous peaks are denoted by red triangles, and they are Xueboding, Jiudingshan, Xuelongbao, Siguniangshan, Haizishan, Gonggashan, Meilixueshan, and Yulongxueshan, respectively, in order. (b) The elevations along the five profiles. 
The Longmenshan, a mountain range in proximity to the Sichuan basin, trends to the northeast along the eastern margin of the Tibetan plateau. Several sub-parallel NNW-trending high mountain ranges also found in the region include Minshan, Qionglaishan, Daxueshan, and Shalulishan. The topography in these mountain ranges is in stark contrast to the very flat central Tibet and has elevations in excess of $5000 \mathrm{~m}$. However, the topography of the eastern margin of the Tibetan plateau is one of the world's most remarkable continental escarpments (Kirby et al., 2003). Elevations are 400-600 $\mathrm{m}$ in the Sichuan basin and 5 500-7 $500 \mathrm{~m}$ at the peaks. The horizontal distance from the basin to the peaks is about $50-80 \mathrm{~km}$ (see the topographic profiles $L_{2}, L_{3}, L_{4}$ in Figures 1 a and 1 b). The topographic gradients at the steep margins exceed $10 \%$. The elevations of the famous peaks are $5582 \mathrm{~m}$ for Xueboding in the Minshan, $4984 \mathrm{~m}$ for Jiudingshan in Longmenshan, $6250 \mathrm{~m}$ for Siguniangshan in Qionglaishan, $5820 \mathrm{~m}$ for Haizishan, $7556 \mathrm{~m}$ for Gonggashan in Daxueshan.

In northeastern and southeastern Tibet, the plateau has no distinct topographic margin. The elevations decrease gradually from about $4500-5000 \mathrm{~m}$ to 1 000-1 $500 \mathrm{~m}$, over several hundred to thousand kilometers without any sudden variation (see the topographic profiles $L_{1}$ to $L_{5}$ from Figure 1).

The steep margin adjacent to the Sichuan basin appears to have uplifted in the past 5-12 Ma, with only minor upper crustal shortening (Burchfiel et al., 1995). Pliocene-Quaternary deformation in eastern Tibet is dominated by left-lateral strike-slip faults that cut across both the topographic gradient of the margin and the trend of older structures (Burchfiel et al., 1995). Along the eastern Tibetan orogenic margin, dynamic stresses that have developed in the deep crust as a consequence of flow of weak lower crust may explain anomalously high topography. The elevated topography of the eastern plateau margin has been proposed to be the direct result of crustal thickening by weak, lower crustal material that has recently been evacuated from beneath the central plateau (Royden et al., 1997; Clark et al., 2005).

Quantitative analyses of regional topographic slopes across the eastern plateau margin indicate that the strength of the middle-lower crust beneath the southeastern and northeastern low-gradient margins is very low. By contrast, the middle-lower crust beneath the steep eastern plateau margin which borders the Sichuan basin is strong. The Sichuan basin, which has been proposed to be high-strength heterogeneities that behave as rigid obstacle to ongoing deformation, often shows concentrated deformation along its margin (Clark et al., 2005).

The regional topographic gradients displayed on a smoothed elevation contour map and 3-D digital topography perspectives show the continental crust 'flowing' from the high central plateau around the low-elevation Sichuan basin, reflecting the flow of weak lower crustal material around a strength heterogeneity in the crust along the eastern margin of Tibet (Figure 1a).

\section{Passive sources seismic obser- vations in the eastern mar- gin of the Tibetan plateau and Sichuan basin}

In order to improve the characterization of crustal heterogeneity and quantitative analyses of the velocities and viscous flow in the deep crust, we have analyzed data from a regional network with about 50 temporary broadband seismometers and 40 permanent seismic stations from the CDSN (Chinese Digital Seismograph Network), which partly belongs to Earthquake Administration of Sichuan Province (Figure 2).

We used data from a network with 90 broadband seismometers. The location of the stations is shown in Figure 2. We analyzed waveforms from seismic events that were selected based on the following criteria: bodywave magnitude $M_{\mathrm{b}}>5.0$, and epicenter distances between $30^{\circ}$ to $100^{\circ}$. A total of 147 events were chosen, mostly from the Circum-Pacific belt and also from the Mediterranean sea and the Indian ocean (Figure 3 ).

The S-wave velocity profiles are derived by receiver function analysis. The receiver function technique has allowed us to derive a source-equalized teleseismic waveform, in which source, far-field path, and instrument effects are removed by deconvolving the vertical component from the radial/transverse components. The resulting receiver function waveform is an estimate of the ground impulse response.

In this study, the following processing steps are applied to derive the receiver functions: rotation, deconvolution, move-out correction, stacking, and filtering (Xu et al., 2007). First, all teleseismic traces are rotated from an $E-N-Z$ coordinate system to an $R-T-Z$ system. Second, we have deconvolved the vertical components from both the radial and transverse components to remove the effects of the source and the instrument. During this process conducted in the frequency domain, 


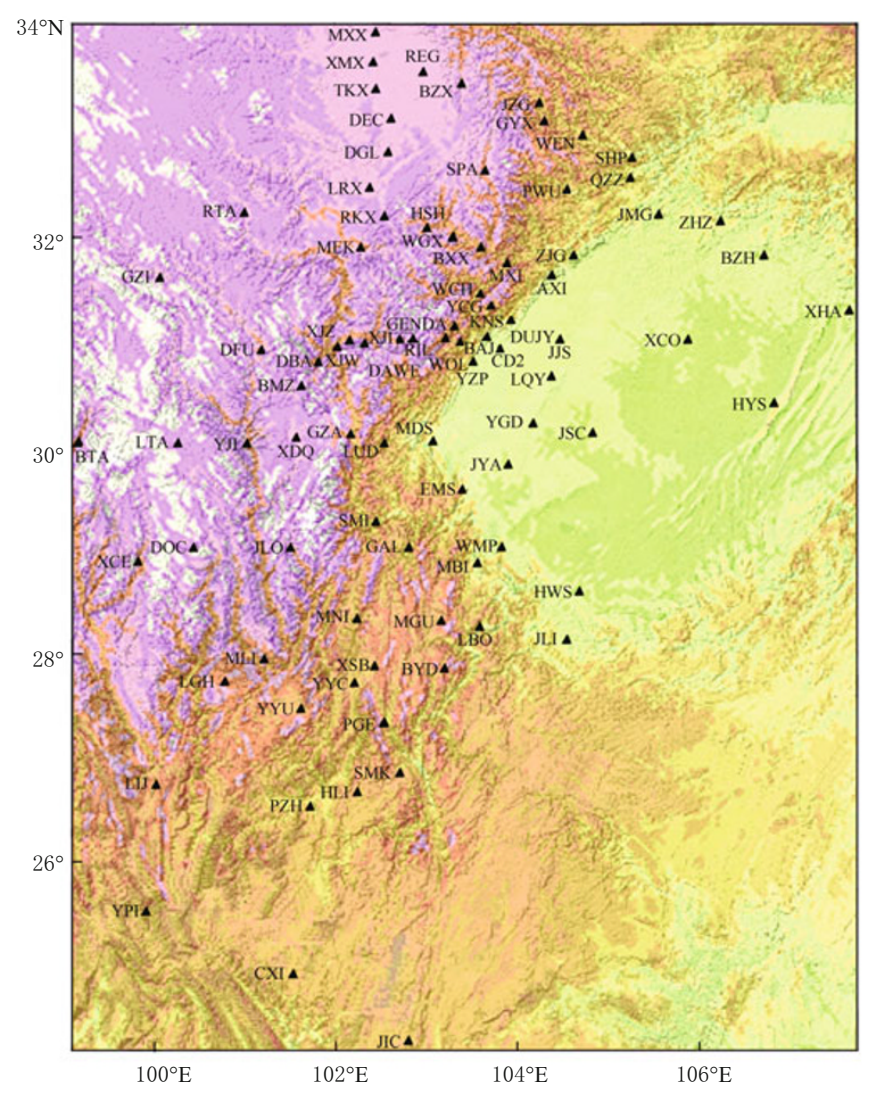

Figure 2 Location of seismic stations (triangles) from regional network of about 50 temporary broadband seismometers and 40 permanent seismic stations of CDSN, partly belonging to Earthquake Administration of Sichuan Province.

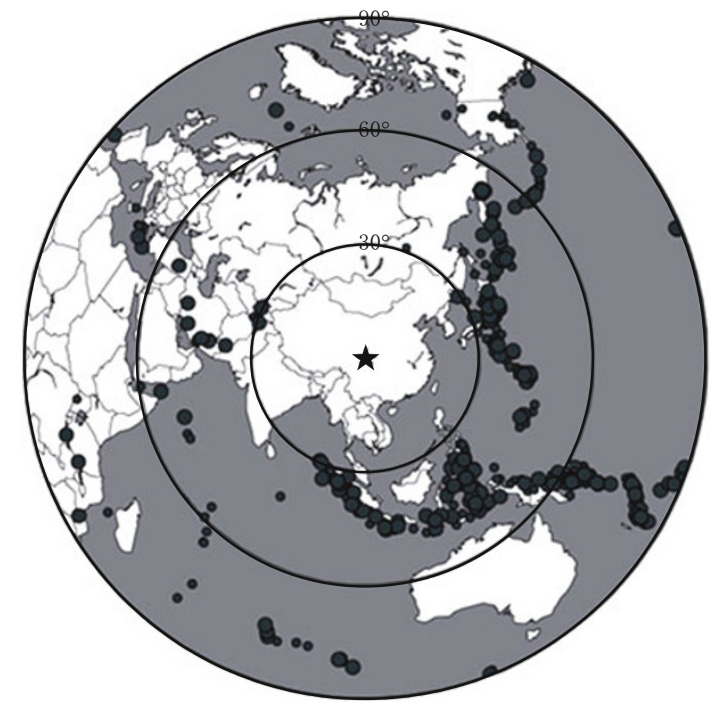

Figure 3 Azimuthal projection centered on the center of study region (black star) showing distribution of events used in this study, recorded over the period from 2005 to 2010. we apply a water level to stabilize the spectral division.

We invert for S-wave velocity structures consisting of horizontal layers with fixed thicknesses of $2 \mathrm{~km}$. Furthermore, we fix the Poisson's ratios and Moho depths at the values derived from the slant-stacking method. The inversion seeks to minimize the difference between the observed and model-generated receiver function waveforms. The $\mathrm{P}$-wave velocity is derived from these results in conjunction with the $v_{\mathrm{P}} / v_{\mathrm{S}}$ ratio. Approximate densities $(\rho)$ throughout the model are derived using the equation $v_{\mathrm{P}}=1.73 v_{\mathrm{S}}, \rho=0.32 v_{\mathrm{P}}+0.77$.

A least-squares inversion of receiver function waveforms is performed to estimate the crustal velocity structure (Ammon et al., 1990). This technique is more sensitive to velocity contrasts than to the absolute magnitude of the velocities, but it requires a starting velocity model that is close to the actual velocities (Owens et al., 1984; Ammon et al., 1990).

Figure 4 shows the typical $v_{\mathrm{S}}$ profiles selected from Table 1. The most striking contrasts of crustal and upper mantle velocity structures are present between the Sichuan basin and the eastern margin of the Tibetan plateau. In the Sichuan basin higher velocity is shown in the crust and upper mantle and we do not find a low velocity zone. The average thickness of the crust is $4044 \mathrm{~km}$. The velocity feature may indicate that the basin is a brittle and rigid block.

The prominent features in the S-wave velocity profiles presented here are the crustal low velocity zones in the eastern margin of the Tibetan plateau. The Moho depth variation is 50 to $66 \mathrm{~km}$.

In the uppermost crust almost ubiquitous low velocity layer can be related to the sedimentary basins or meta-sedimentary rocks. The crustal low velocity zone is widely distributed in the eastern margin of the Tibetan plateau, but with significant lateral variation in its depth and strength. In some regions the low velocity zone corresponds to the middle crust, but in other places it marks the lower crust (Xu et al., 2007). The low velocity zone in the middle and lower crust indicates that the rock has ductile properties, and deforms easily.

Figure 5 shows the crustal thickness in the eastern margin of the Tibetan plateau and Sichuan basin. The thickest crust is found in the central part of the eastern margin of Tibetan plateau $(\sim 64-66 \mathrm{~km})$, and is also found the thicker low velocity zone in the middle to lower crust. In surface morphology this region shows the highest mountain ranges and peaks (Gonggashan, Siguniangshan), adjacent to the boundary of the Sichuan basin. Along the boundary of eastern 
Table 1 Station and receiver function analysis results for the $v_{\mathrm{S}}$ velocity distribution with individual depth $d$ (in unit of $\mathrm{km})$ in the crust and upper mantle

\begin{tabular}{|c|c|c|c|c|c|c|c|c|c|c|c|c|}
\hline \multirow{2}{*}{ Station } & \multirow{2}{*}{$\begin{array}{l}\text { Long. } \\
/\left({ }^{\circ} \mathrm{E}\right)\end{array}$} & \multirow{2}{*}{$\begin{array}{l}\text { Lat. } \\
/\left({ }^{\circ} \mathrm{N}\right)\end{array}$} & \multirow{2}{*}{$\begin{array}{l}\text { Elev. } \\
/ \mathrm{m}\end{array}$} & \multirow{2}{*}{$\begin{array}{c}\text { Moho } \\
\text { depth/km }\end{array}$} & \multicolumn{8}{|c|}{$v_{\mathrm{S}} /\left(\mathrm{km} \cdot \mathrm{s}^{-1}\right)$} \\
\hline & & & & & $d=0$ & $d=10$ & $d=20$ & $d=30$ & $d=40$ & $d=50$ & $d=60$ & $d=80$ \\
\hline \multicolumn{13}{|c|}{ Sichuan basin } \\
\hline BAJ & 103.40 & 30.98 & 1361 & 44 & 2.5 & 3.2 & 3.5 & 3.5 & 4.1 & 4.6 & 4.6 & 4.6 \\
\hline DUJY & 103.61 & 31.03 & 1300 & 44 & 2.8 & 3.3 & 3.3 & 3.6 & 4.1 & 4.6 & 4.6 & 4.6 \\
\hline JSC & 104.81 & 30.13 & 444 & 42 & 2.8 & 3.3 & 3.7 & 3.7 & 3.7 & 4.3 & 4.3 & 4.3 \\
\hline KNS & 103.90 & 31.12 & 834 & 44 & 2.7 & 3.2 & 3.6 & 3.8 & 3.8 & 4.3 & 4.3 & 4.5 \\
\hline LQY & 104.35 & 30.62 & 700 & 42 & 2.6 & 2.9 & 3.7 & 3.7 & 4.2 & 4.5 & 4.5 & 4.5 \\
\hline YCG & 103.81 & 31.26 & 1175 & 44 & 2.9 & 3.3 & 3.7 & 3.7 & 3.9 & 4.3 & 4.3 & 4.3 \\
\hline ZHZ & 106.20 & 32.18 & 613 & 42 & 2.7 & 3.1 & 3.6 & 3.6 & 3.8 & 4.1 & 4.1 & 4.5 \\
\hline QZZ & 105.23 & 32.59 & 805 & 44 & 2.7 & 3.0 & 3.6 & 3.6 & 3.9 & 4.2 & 4.2 & 4.5 \\
\hline SHP & 105.28 & 32.70 & 817 & 44 & 3.0 & 3.4 & 3.5 & 3.5 & 3.8 & 4.3 & 4.3 & 4.5 \\
\hline AXI & 104.43 & 31.64 & 587 & 42 & 3.0 & 3.5 & 3.8 & 4.3 & 4.3 & 4.7 & 4.7 & 4.7 \\
\hline $\mathrm{BZH}$ & 106.74 & 31.84 & 442 & 42 & 3.0 & 3.4 & 4.0 & 4.0 & 4.0 & 4.6 & 4.6 & 4.6 \\
\hline CD2 & 103.75 & 30.91 & 692 & 43 & 2.4 & 3.0 & 3.6 & 3.6 & 4.1 & 4.7 & 4.7 & 4.7 \\
\hline HWS & 104.74 & 28.64 & 860 & 40 & 3.3 & 3.3 & 3.8 & 3.8 & 4.1 & 4.7 & 4.7 & 4.7 \\
\hline HYS & 106.84 & 30.42 & 555 & 41 & 3.1 & 3.2 & 3.9 & 3.9 & 4.1 & 4.7 & 4.7 & 4.7 \\
\hline JMG & 105.56 & 32.21 & 801 & 42 & 2.8 & 3.3 & 3.9 & 3.8 & 3.8 & 4.6 & 4.8 & 4.8 \\
\hline JJS & 104.55 & 31.00 & 908 & 42 & 2.7 & 3.3 & 3.7 & 4.1 & 4.1 & 4.8 & 4.8 & 4.8 \\
\hline JYA & 103.93 & 29.79 & 570 & 42 & 2.6 & 3.4 & 4.0 & 4.1 & 4.1 & 4.4 & 4.4 & 4.4 \\
\hline JLI & 104.52 & 28.18 & 480 & 42 & 3.1 & 3.5 & 3.5 & 3.7 & 4.0 & 4.8 & 4.8 & 4.8 \\
\hline MDS & 103.04 & 30.07 & 1210 & 42 & 2.7 & 3.5 & 3.9 & 3.9 & 3.9 & 4.4 & 4.4 & 4.7 \\
\hline $\mathrm{XCO}$ & 105.90 & 31.02 & 336 & 40 & 2.9 & 3.3 & 3.8 & 3.8 & 4.0 & 4.6 & 4.8 & 4.8 \\
\hline XHA & 107.72 & 31.37 & 390 & 42 & 2.9 & 3.3 & 3.6 & 3.6 & 3.8 & 4.3 & 4.8 & 4.8 \\
\hline YGD & 104.10 & 30.20 & 800 & 42 & 2.8 & 3.5 & 3.8 & 4.1 & 4.1 & 4.8 & 4.8 & 4.8 \\
\hline YZP & 103.57 & 30.87 & 766 & 44 & 2.6 & 3.4 & 3.8 & 3.8 & 3.9 & 4.8 & 4.8 & 4.8 \\
\hline ZJG & 104.67 & 31.79 & 612 & 42 & 3.0 & 3.5 & 3.6 & 4.1 & 4.1 & 4.8 & 4.8 & 4.8 \\
\hline EMS & 103.45 & 29.58 & 467 & 42 & 2.7 & 3.5 & 3.5 & 3.7 & 3.7 & 4.3 & 4.3 & 4.6 \\
\hline \multicolumn{13}{|c|}{ Northern part of the eastern margin of Tibetan plateau } \\
\hline MXX & 102.45 & 34.02 & 3436 & 52 & 3.3 & 3.6 & 3.3 & 3.1 & 3.1 & 3.7 & 3.7 & 4.0 \\
\hline REG & 102.96 & 33.58 & 3470 & 52 & 3.2 & 3.7 & 3.7 & 3.4 & 3.4 & 3.8 & 4.5 & 4.7 \\
\hline BZX & 103.36 & 33.47 & 3457 & 52 & 3.1 & 3.9 & 3.7 & 3.7 & 4.1 & 4.1 & 4.6 & 4.6 \\
\hline TKX & 102.47 & 33.41 & 3411 & 52 & 3.3 & 4.2 & 3.0 & 3.6 & 3.0 & 4.0 & 4.2 & 4.2 \\
\hline JZG & 104.24 & 33.28 & 1440 & 52 & 2.8 & 3.7 & 3.7 & 3.4 & 3.4 & 3.8 & 4.2 & 4.2 \\
\hline GYX & 104.33 & 33.12 & 1260 & 50 & 2.9 & 4.1 & 3.4 & 3.4 & 3.4 & 4.4 & 4.4 & 4.6 \\
\hline WEN & 104.68 & 32.95 & 910 & 48 & 3.2 & 3.5 & 3.2 & 3.2 & 3.2 & 4.3 & 4.3 & 4.3 \\
\hline DGL & 102.53 & 32.81 & 3482 & 52 & 3.1 & 3.4 & 3.1 & 3.1 & 3.1 & 3.9 & 3.9 & 3.9 \\
\hline SPA & 103.60 & 32.65 & 2905 & 60 & 3.2 & 3.5 & 3.7 & 3.7 & 3.7 & 3.9 & 4.3 & 4.3 \\
\hline LRX & 102.44 & 32.49 & 3566 & 54 & 3.1 & 3.5 & 3.5 & 3.0 & 3.0 & 3.8 & 3.8 & 3.8 \\
\hline PWU & 104.55 & 32.42 & 882 & 44 & 3.5 & 3.7 & 3.6 & 3.6 & 3.6 & 4.1 & 4.1 & 4.3 \\
\hline RTA & 100.98 & 32.27 & 3317 & 60 & 3.1 & 3.7 & 3.7 & 3.3 & 3.3 & 3.8 & 4.2 & 4.5 \\
\hline RKX & 102.49 & 32.21 & 3539 & 54 & 2.8 & 3.3 & 3.4 & 3.0 & 3.0 & 3.4 & 3.4 & 3.9 \\
\hline HSH & 102.99 & 32.06 & 2344 & 54 & 3.4 & 3.6 & 3.8 & 3.3 & 3.3 & 3.3 & 4.0 & 4.3 \\
\hline WGX & 103.34 & 31.98 & 1904 & 54 & 3.0 & 3.3 & 3.0 & 3.0 & 3.5 & 3.5 & 4.0 & 4.0 \\
\hline MEK & 102.22 & 31.90 & 2765 & 58 & 3.0 & 3.4 & 3.5 & 3.9 & 3.7 & 3.7 & 4.5 & 4.5 \\
\hline BXX & 103.54 & 31.88 & 1820 & 54 & 2.7 & 3.1 & 3.0 & 3.0 & 3.5 & 3.5 & 3.9 & 3.9 \\
\hline MXI & 103.85 & 31.69 & 1584 & 46 & 3.1 & 3.2 & 3.2 & 3.2 & 3.8 & 4.5 & 4.5 & 4.5 \\
\hline WCH & 103.59 & 31.47 & 1315 & 48 & 3.6 & 3.5 & 3.5 & 3.5 & 3.9 & 3.8 & 4.3 & 4.3 \\
\hline
\end{tabular}


Continued on from Table 1

\begin{tabular}{|c|c|c|c|c|c|c|c|c|c|c|c|c|}
\hline \multirow{2}{*}{ Station } & \multirow{2}{*}{$\begin{array}{l}\text { Long. } \\
/\left({ }^{\circ} \mathrm{E}\right)\end{array}$} & \multirow{2}{*}{$\begin{array}{l}\text { Lat. } \\
/\left({ }^{\circ} \mathrm{N}\right)\end{array}$} & \multirow{2}{*}{$\begin{array}{r}\text { Elev. } \\
/ \mathrm{m}\end{array}$} & \multirow{2}{*}{$\begin{array}{c}\text { Moho } \\
\text { depth/km }\end{array}$} & \multicolumn{8}{|c|}{$v_{\mathrm{S}} /\left(\mathrm{km} \cdot \mathrm{s}^{-1}\right)$} \\
\hline & & & & & $d=0$ & $d=10$ & $d=20$ & $d=30$ & $d=40$ & $d=50$ & $d=60$ & $d=80$ \\
\hline \multicolumn{13}{|c|}{ Central part of the eastern margin of Tibetan plateau } \\
\hline GENDA & 103.28 & 31.10 & 1520 & 52 & 3.0 & 3.4 & 3.2 & 3.2 & 3.9 & 3.9 & 4.4 & 4.4 \\
\hline WOL & 103.17 & 31.02 & 2019 & 50 & 3.2 & 3.8 & 3.0 & 3.0 & 3.3 & 4.1 & 3.3 & 3.3 \\
\hline RIL & 102.77 & 31.00 & 3026 & 62 & 3.1 & 3.3 & 3.0 & 3.0 & 3.6 & 3.8 & 3.8 & 4.2 \\
\hline DAWE & 102.63 & 30.97 & 2773 & 62 & 3.0 & 3.4 & 3.4 & 3.0 & 3.6 & 3.6 & 3.6 & 4.3 \\
\hline XJI & 102.36 & 31.00 & 2427 & 66 & 3.4 & 4.0 & 3.5 & 3.5 & 3.5 & 4.0 & 4.0 & 4.4 \\
\hline XJZ & 102.09 & 31.00 & 2101 & 66 & 3.1 & 3.4 & 3.6 & 3.1 & 3.4 & 3.6 & 3.8 & 4.1 \\
\hline XJW & 102.00 & 30.97 & 2004 & 66 & 3.4 & 3.4 & 4.4 & 3.4 & 3.5 & 3.4 & 3.5 & 4.4 \\
\hline DBA & 101.75 & 30.80 & 2895 & 62 & 2.7 & 3.3 & 3.0 & 2.9 & 3.7 & 3.4 & 4.0 & 4.3 \\
\hline BMZ & 101.53 & 30.55 & 3612 & 64 & 3.0 & 3.3 & 2.6 & 2.6 & 3.5 & 3.5 & 3.5 & 4.1 \\
\hline $\mathrm{DFU}$ & 101.12 & 30.91 & 3035 & 64 & 3.1 & 3.4 & 3.4 & 3.1 & 3.1 & 3.7 & 4.1 & 4.4 \\
\hline BTA & 99.12 & 30.01 & 2639 & 60 & 2.8 & 3.6 & 3.2 & 3.2 & 3.2 & 3.6 & 3.9 & 3.9 \\
\hline $\mathrm{XCE}$ & 99.79 & 28.94 & 3000 & 62 & 2.8 & 3.5 & 3.5 & 3.5 & 4.1 & 4.1 & 4.1 & 4.7 \\
\hline GZI & 100.02 & 31.61 & 3360 & 60 & 2.7 & 3.2 & 2.8 & 2.8 & 3.4 & 3.9 & 4.2 & 4.2 \\
\hline LTA & 100.27 & 30.00 & 3951 & 62 & 3.1 & 3.6 & 3.6 & 3.4 & 3.4 & 4.2 & 4.2 & 4.7 \\
\hline YJI & 101.01 & 30.03 & 2670 & 64 & 3.2 & 3.7 & 3.7 & 3.4 & 3.4 & 3.8 & 3.8 & 4.2 \\
\hline JLO & 101.51 & 29.00 & 2915 & 60 & 3.3 & 3.3 & 3.7 & 3.3 & 3.3 & 3.3 & 3.4 & 3.6 \\
\hline GZA & 102.17 & 30.12 & 1410 & 60 & 3.3 & 3.7 & 3.7 & 3.4 & 3.2 & 3.2 & 3.7 & 3.9 \\
\hline SMI & 102.35 & 29.22 & 860 & 58 & 2.9 & 3.4 & 3.6 & 3.3 & 3.3 & 3.8 & 4.0 & 4.3 \\
\hline \multicolumn{13}{|c|}{ Southern part of the eastern margin of Tibetan plateau } \\
\hline BYD & 103.19 & 27.81 & 3160 & 52 & 2.9 & 3.3 & 3.5 & 3.5 & 3.5 & 3.8 & 4.1 & 4.6 \\
\hline HLI & 102.25 & 26.65 & 1836 & 52 & 3.1 & 3.4 & 3.7 & 3.7 & 3.7 & 4.0 & 4.4 & 4.6 \\
\hline $\mathrm{LBO}$ & 103.57 & 28.27 & 1310 & 50 & 3.0 & 3.3 & 3.4 & 3.7 & 4.1 & 4.1 & 4.5 & 4.7 \\
\hline LGH & 100.86 & 27.71 & 2669 & 54 & 3.2 & 3.5 & 3.6 & 3.6 & 3.8 & 3.8 & 4.6 & 4.6 \\
\hline MBI & 103.53 & 28.84 & 640 & 50 & 3.1 & 3.6 & 3.8 & 3.8 & 4.1 & 4.1 & 4.6 & 4.6 \\
\hline MGU & 103.13 & 28.33 & 2056 & 56 & 3.2 & 3.8 & 3.8 & 3.9 & 3.9 & 4.2 & 4.5 & 4.7 \\
\hline WMP & 103.79 & 29.05 & 1260 & 46 & 3.2 & 3.4 & 3.7 & 3.7 & 3.7 & 4.5 & 4.5 & 4.5 \\
\hline XSB & 102.45 & 27.86 & 2800 & 52 & 3.2 & 3.4 & 3.8 & 3.8 & 4.0 & 4.0 & 4.2 & 4.6 \\
\hline YYC & 102.26 & 27.85 & 1608 & 52 & 3.0 & 3.3 & 3.8 & 3.8 & 4.1 & 4.1 & 4.2 & 4.5 \\
\hline MNI & 102.17 & 28.33 & 1657 & 50 & 3.0 & 3.6 & 3.6 & 3.9 & 3.9 & 3.9 & 4.2 & 4.9 \\
\hline MLI & 101.27 & 27.93 & 2437 & 54 & 3.3 & 3.3 & 4.2 & 3.3 & 3.3 & 3.3 & 4.1 & 4.7 \\
\hline $\mathrm{PZH}$ & 101.74 & 26.50 & 1190 & 54 & 3.4 & 3.7 & 3.7 & 3.3 & 3.3 & 4.1 & 4.5 & 4.7 \\
\hline PGE & 102.54 & 27.38 & 1427 & 52 & 3.3 & 3.7 & 3.2 & 3.2 & 3.8 & 3.8 & 4.6 & 4.6 \\
\hline SMK & 102.75 & 26.86 & 2360 & 50 & 3.0 & 3.7 & 3.7 & 3.3 & 3.3 & 4.1 & 4.7 & 4.7 \\
\hline YYU & 101.68 & 27.47 & 2596 & 50 & 3.2 & 3.8 & 4.0 & 3.6 & 3.6 & 3.8 & 4.5 & 4.5 \\
\hline LUD & 102.50 & 30.00 & 1330 & 57 & 3.0 & 3.2 & 3.1 & 3.1 & 3.1 & 3.4 & 3.4 & 4.5 \\
\hline XDQ & 101.50 & 30.10 & 3667 & 61 & 3.0 & 3.1 & 3.1 & 3.1 & 3.5 & 3.5 & 4.6 & 4.6 \\
\hline LIJ & 100.00 & 26.80 & 2416 & 55 & 3.1 & 3.4 & 3.1 & 3.1 & 3.1 & 4.3 & 4.3 & 4.4 \\
\hline DOC & 100.40 & 29.00 & 4448 & 62 & 3.1 & 3.3 & 3.2 & 3.7 & 3.7 & 3.7 & 4.4 & 4.5 \\
\hline YPI & 99.60 & 25.50 & 2250 & 41 & 2.9 & 3.8 & 3.7 & 3.7 & 3.7 & 4.7 & 4.8 & 4.8 \\
\hline CXI & 101.50 & 24.90 & 1890 & 50 & 2.9 & 3.8 & 3.8 & 3.8 & 3.8 & 4.7 & 4.7 & 4.7 \\
\hline JIC & 102.80 & 24.20 & 1806 & 42 & 2.8 & 3.2 & 3.2 & 3.2 & 4.7 & 4.7 & 4.7 & 4.7 \\
\hline
\end{tabular}

Notes: The $v_{\mathrm{S}}$ velocity values of last five stations are from $\mathrm{Xu}$ et al. (2007).

margin of the Tibetan plateau and the Sichuan basin the Moho discontinuity has a large displacement gradient from $42 \mathrm{~km}$ to $60 \mathrm{~km}$ in depth. The crust beneath the Sichuan basin has a thickness of $\sim 40-44 \mathrm{~km}$. In the southern part of the eastern margin of Tibetan plateau the crustal thickness varies from $54 \mathrm{~km}$ to $38 \mathrm{~km}$ and gradually thins to the southeast.

Poisson's ratios can help to constrain crustal properties and chemical composition (Zhu and Kanamori, 2000). We interpret the large range of observed Pois- 
son's ratio in the eastern margin of the Tibetan plateau and Sichuan basin (see Table 2) to be a result of heterogeneity in crustal composition and, locally, the existence of partial-melt. Most of our study region has an intermediate to high Poisson's ratio (0.24-0.35). All these suggest the presence of complex heterogeneity in the crust beneath the eastern margin of the Tibetan plateau and the Sichuan basin.
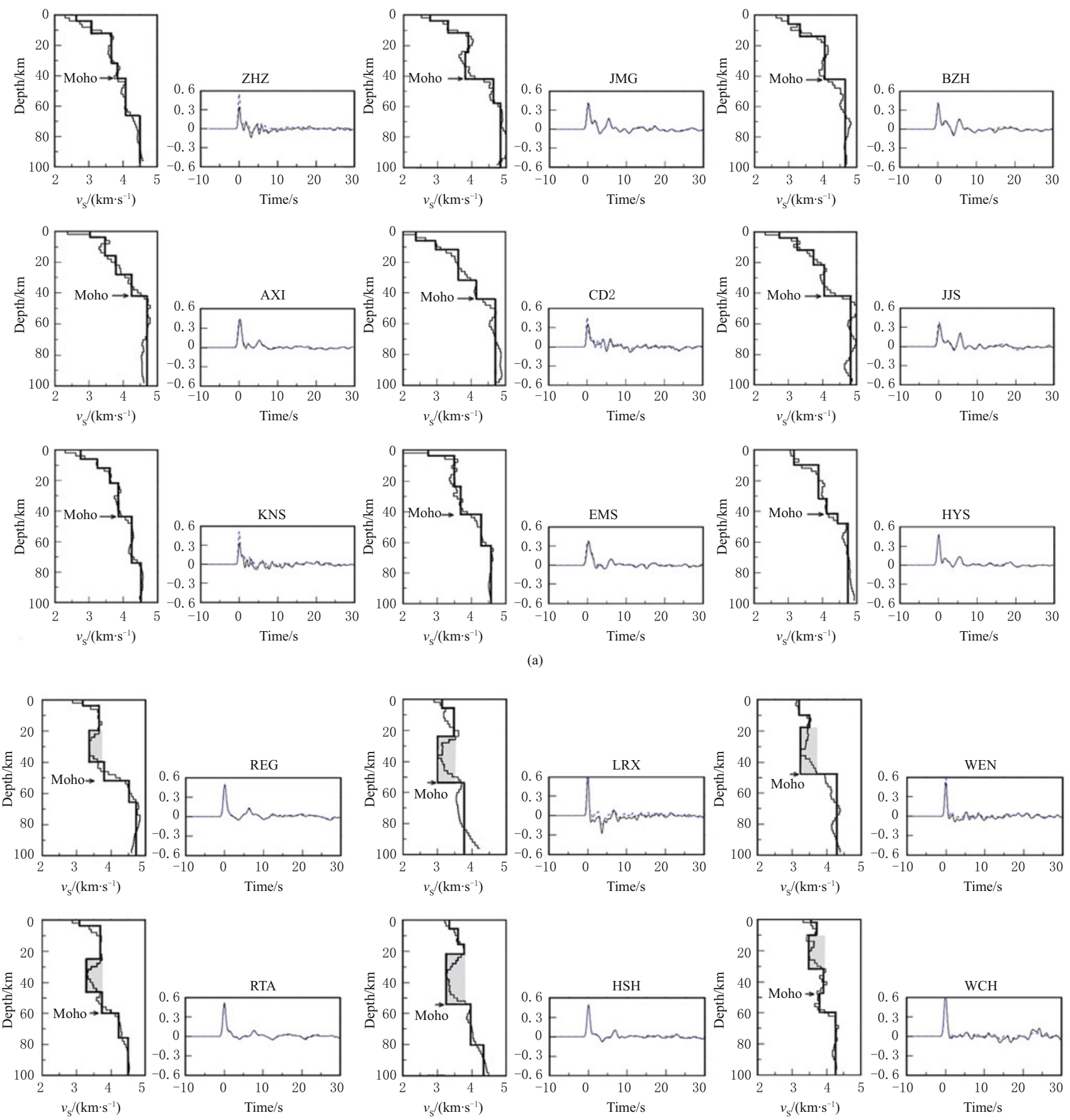

(b)

Figure 4 Typical $v_{\mathrm{S}}$ velocity profiles in Sichuan basin (a), northern part (b), central part (c) and southern part of the eastern margin of Tibetan plateau. Data are from Table 1. The red shadow in the profiles indicates the low velocity zone. In the Sichuan basin all $v_{\mathrm{S}}$ profiles indicate the higher velocity and no low velocity zone in the crust and upper mantle. In the eastern margin of the Tibetan plateau most of the $v_{\mathrm{S}}$ profiles indicate the lower velocity in the crust and upper mantle. 

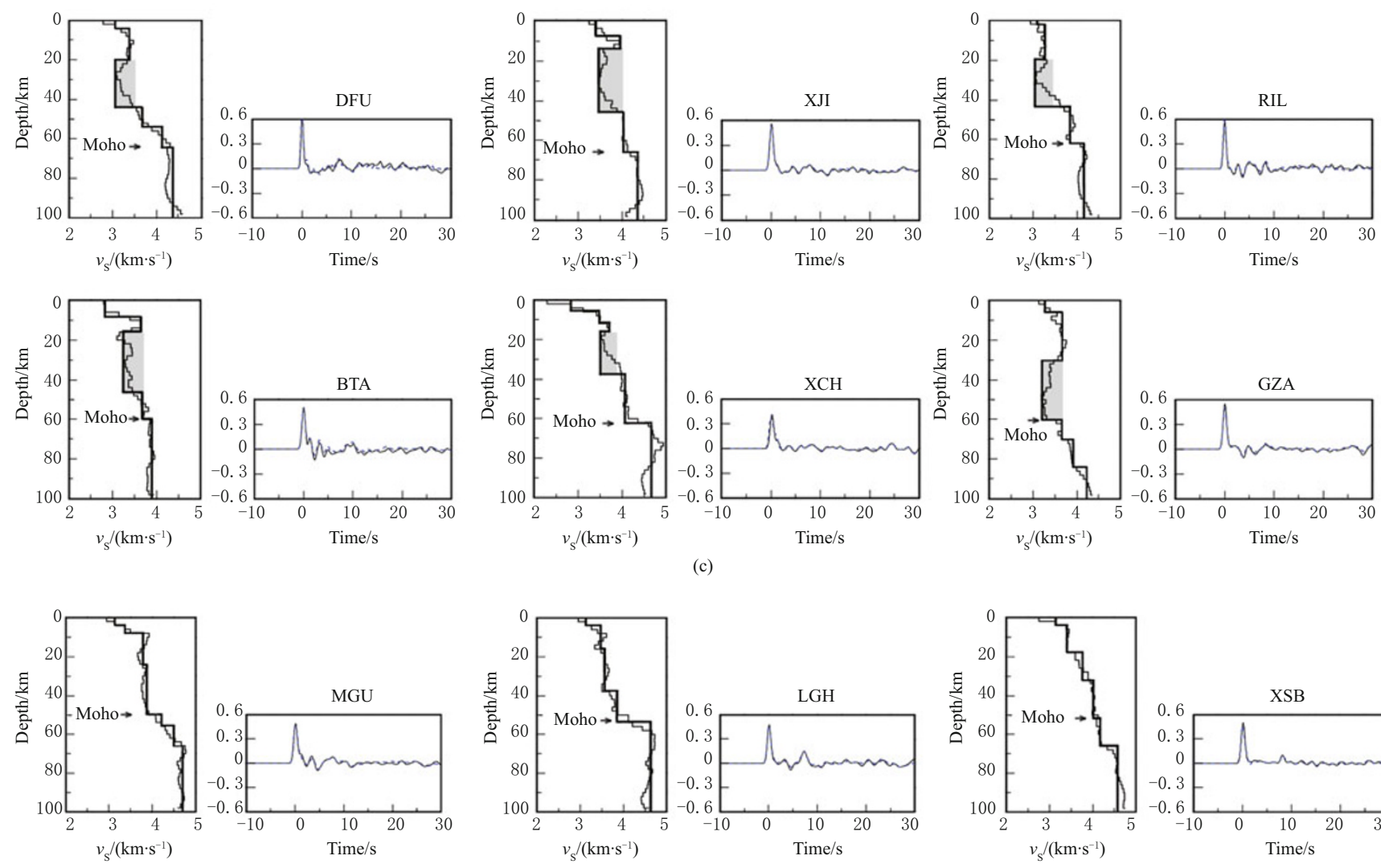

(c)
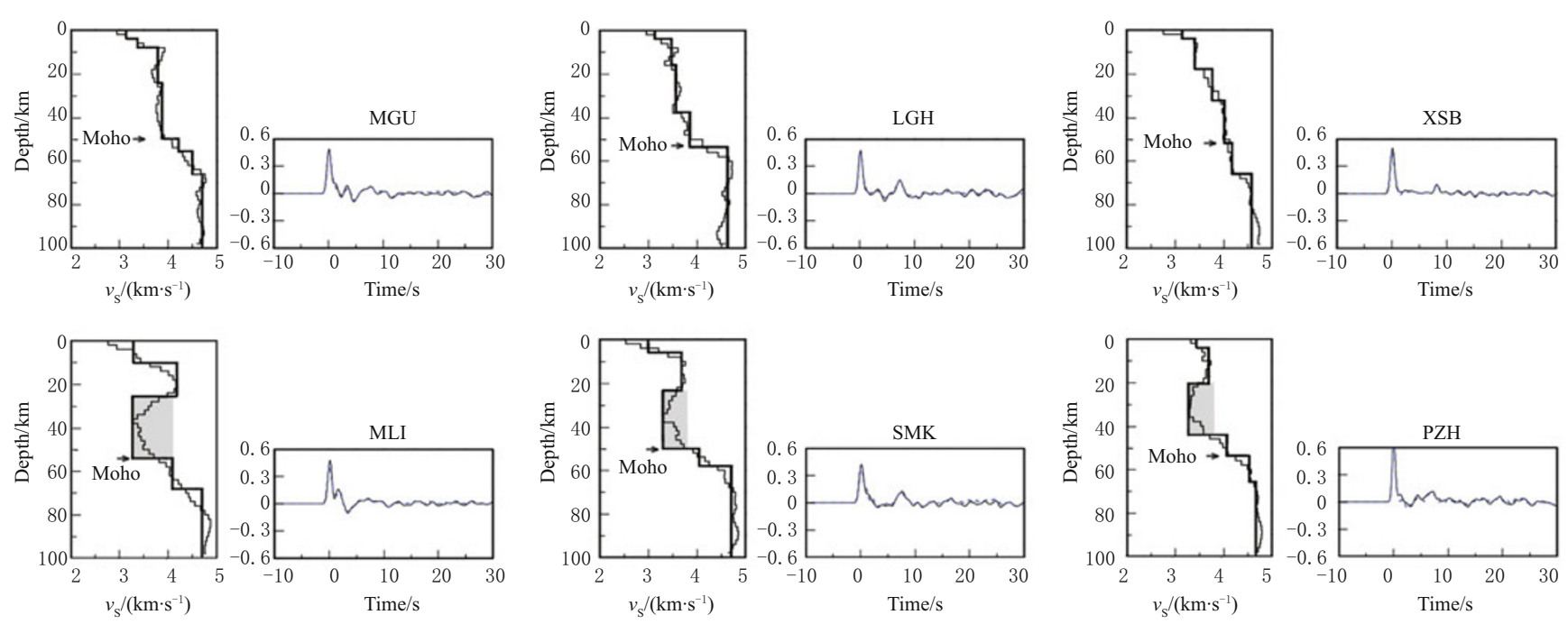

(d)

Figure 4 Typical $v_{\mathrm{S}}$ velocity profiles in Sichuan basin (a), northern part (b), central part (c) and southern part of the eastern margin of Tibetan plateau. Data are from Table 1. The red shadow in the profiles indicates the low velocity zone. In the Sichuan basin all $v_{\mathrm{S}}$ profiles indicate the higher velocity and no low velocity zone in the crust and upper mantle. In the eastern margin of the Tibetan plateau most of the $v_{\mathrm{S}}$ profiles indicate the lower velocity in the crust and upper mantle.

The most prominent features are the strong and rigid crust and upper mantle beneath the Sichuan basin, indicating the normal value of Poisson's ratios generally decreasing from 0.28 to 0.24 .

The ratio is higher in most of the eastern margin of the plateau. The normal-to-high Poisson's ratios (0.240.34 ) were found in the northern part of this region, and very high values $(0.30-0.35)$ in the central part. In the south part of the eastern margin, the Poisson's ratio exhibits more significant variation (0.23-0.34).
The results suggest that the presence of complex heterogeneity in the crust beneath the eastern margin of Tibetan plateau and Sichuan basin. The most prominent feature in this region is that the Sichuan basin exhibits strong and rigid crust and upper mantle. The central part of the eastern margin of Tibetan plateau indicates the presence of partial-melt in the middle and lower crust, whereas the variation of the ratio in the northern and southern parts indicates the higher heterogeneity in the crust and upper mantle in this region. 
Table $2 \quad v_{\mathrm{P}} / v_{\mathrm{S}}$ ratio and Poisson's ratio in the Sichuan basin and the eastern margin of the Tibetan plateau

\begin{tabular}{|c|c|c|c|c|c|}
\hline Station & Long. $/\left({ }^{\circ} \mathrm{E}\right)$ & Lat. $/\left({ }^{\circ} \mathrm{N}\right)$ & $v_{\mathrm{P}} / v_{\mathrm{S}}$ ratio & Poisson's ratio & Moho depth \\
\hline \multicolumn{6}{|c|}{ Sichuan basin } \\
\hline BAJ & 103.40 & 30.98 & 1.71 & 0.24 & 44 \\
\hline YCG & 103.81 & 31.26 & 1.80 & 0.28 & 44 \\
\hline AXI & 104.43 & 31.64 & 1.73 & 0.25 & 42 \\
\hline $\mathrm{BZH}$ & 106.74 & 31.84 & 1.72 & 0.24 & 42 \\
\hline HWS & 104.74 & 28.64 & 1.79 & 0.27 & 40 \\
\hline HYS & 106.84 & 30.42 & 1.80 & 0.28 & 41 \\
\hline JMG & 105.56 & 32.21 & 1.77 & 0.27 & 42 \\
\hline JJS & 104.55 & 31.00 & 1.82 & 0.28 & 42 \\
\hline JLI & 104.52 & 28.18 & 1.68 & 0.23 & 42 \\
\hline MDS & 103.04 & 30.07 & 1.72 & 0.24 & 42 \\
\hline XHA & 107.72 & 31.37 & 1.76 & 0.26 & 42 \\
\hline ZJG & 104.67 & 31.79 & 1.74 & 0.25 & 42 \\
\hline \multicolumn{6}{|c|}{ Northern part of the eastern margin of Tibetan plateau } \\
\hline MXX & 102.45 & 34.02 & 1.77 & 0.27 & 52 \\
\hline REG & 102.96 & 33.58 & 1.78 & 0.27 & 52 \\
\hline DGL & 102.53 & 32.81 & 1.76 & 0.26 & 52 \\
\hline LRX & 102.44 & 32.49 & 1.75 & 0.26 & 54 \\
\hline PWU & 104.55 & 32.42 & 1.67 & 0.22 & 44 \\
\hline RTA & 100.98 & 32.27 & 1.80 & 0.28 & 60 \\
\hline RKX & 102.49 & 32.21 & 1.80 & 0.28 & 54 \\
\hline HSH & 102.99 & 32.06 & 1.72 & 0.24 & 54 \\
\hline WGX & 103.34 & 31.98 & 1.74 & 0.25 & 54 \\
\hline MEK & 102.22 & 31.90 & 1.71 & 0.24 & 58 \\
\hline MXI & 103.85 & 31.69 & 1.79 & 0.27 & 46 \\
\hline $\mathrm{WCH}$ & 103.59 & 31.47 & 2.05 & 0.34 & 48 \\
\hline \multicolumn{6}{|c|}{ Central part of the eastern margin of Tibetan plateau } \\
\hline RIL & 102.77 & 31.00 & 2.10 & 0.35 & 62 \\
\hline DAWE & 102.63 & 30.97 & 2.25 & 0.38 & 62 \\
\hline XJI & 102.36 & 31.00 & 1.82 & 0.28 & 66 \\
\hline XJZ & 102.09 & 31.00 & 1.80 & 0.28 & 66 \\
\hline XJW & 102.00 & 30.97 & 1.88 & 0.30 & 66 \\
\hline DBA & 101.75 & 30.80 & 1.84 & 0.29 & 62 \\
\hline $\mathrm{BMZ}$ & 101.53 & 30.55 & 2.10 & 0.35 & 64 \\
\hline $\mathrm{DFU}$ & 101.12 & 30.91 & 1.80 & 0.28 & 64 \\
\hline GZI & 100.02 & 31.61 & 1.91 & 0.31 & 60 \\
\hline LTA & 100.27 & 30.00 & 1.93 & 0.32 & 62 \\
\hline YJI & 101.01 & 30.03 & 1.85 & 0.29 & 64 \\
\hline GZA & 102.17 & 30.12 & 1.84 & 0.29 & 60 \\
\hline SMI & 102.35 & 29.22 & 1.88 & 0.30 & 58 \\
\hline \multicolumn{6}{|c|}{ Southern part of the eastern margin of Tibetan plateau } \\
\hline BYD & 103.19 & 27.81 & 1.68 & 0.23 & 52 \\
\hline HLI & 102.25 & 26.65 & 1.68 & 0.23 & 52 \\
\hline LBO & 103.57 & 28.27 & 1.70 & 0.24 & 50 \\
\hline LGH & 100.86 & 27.71 & 1.79 & 0.27 & 54 \\
\hline MBI & 103.53 & 28.84 & 1.74 & 0.25 & 50 \\
\hline WMP & 103.79 & 29.05 & 1.79 & 0.27 & 46 \\
\hline SMK & 102.75 & 26.86 & 1.78 & 0.27 & 50 \\
\hline XSB & 102.45 & 27.86 & 1.90 & 0.31 & 52 \\
\hline MNI & 102.17 & 28.33 & 2.01 & 0.34 & 50 \\
\hline $\mathrm{PZH}$ & 101.74 & 26.50 & 1.98 & 0.33 & 54 \\
\hline PGE & 102.54 & 27.38 & 1.94 & 0.32 & 52 \\
\hline YYU & 101.68 & 27.47 & 1.95 & 0.32 & 50 \\
\hline
\end{tabular}




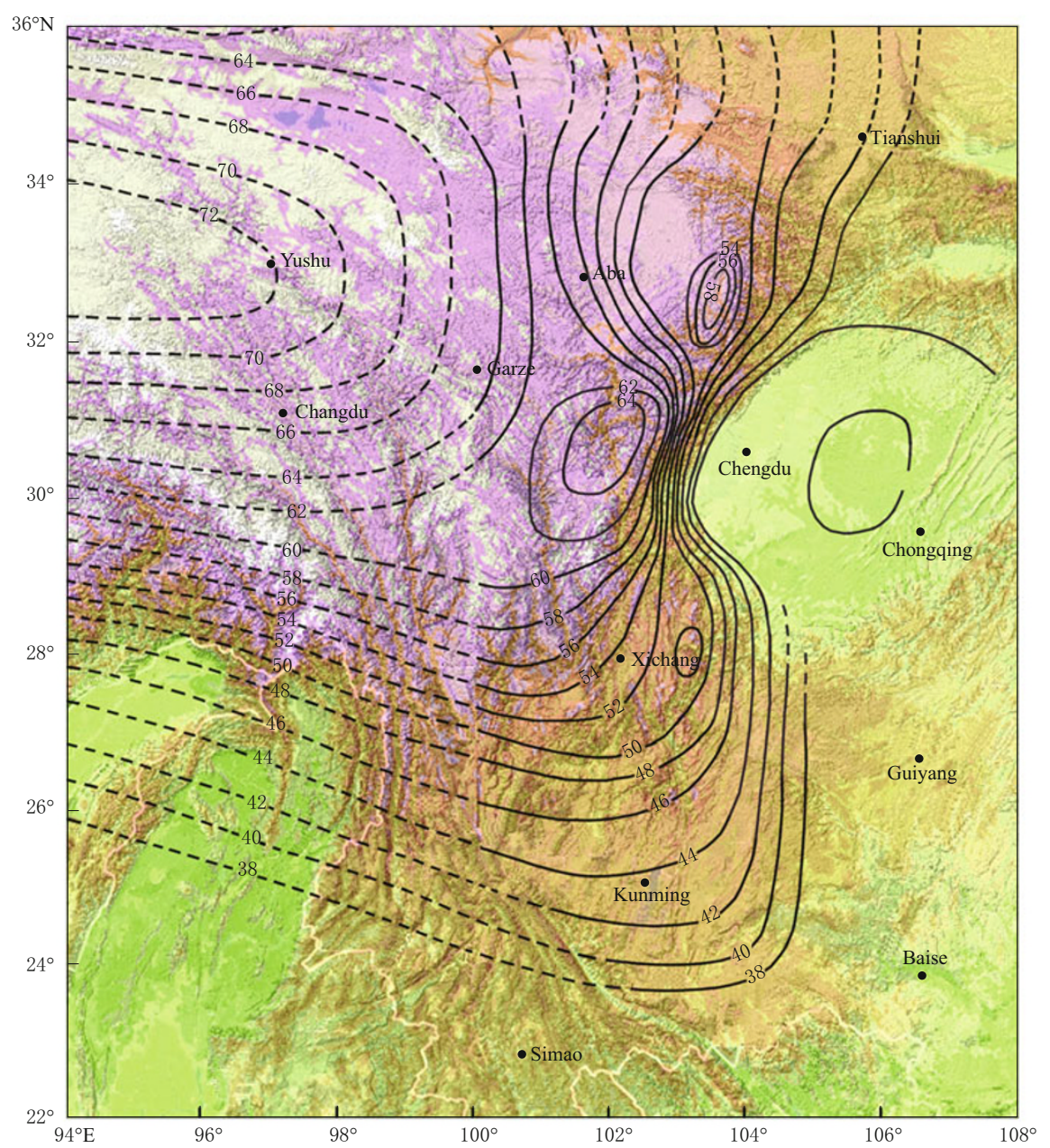

Figure 5 Contour map of crustal thickness (in $\mathrm{km}$ ). The solid line is from this receiver function study. The dashed line is from inversion of Bouguer gravity anomaly data or explosion seismic data.

\section{Viscous flows within the mid- dle and lower crust around the Sichuan basin}

From 0 to $10 \mathrm{~km}, v_{\mathrm{S}}$ is lower in the Sichuan basin because the basin has huge thickness of sediments that are characterized by low velocity. In contrast, the mountain ranges in the eastern margin of the Tibetan plateau show higher velocities. For 10-40 km the Sichuan basin shows higher $v_{\mathrm{S}}$ velocity in the middle and lower crust whereas the eastern margin of the Tibetan plateau shows lower velocity. For $50-60 \mathrm{~km}$ the Sichuan basin extends to the upper mantle showing high velocity. Still in this depth range low velocities are found in the lower crustal portion of the eastern margin of the Tibetan plateau. At $80 \mathrm{~km}$ depth, upper mantle is present in both regions, but the velocity distribution indicates the obvious difference. In the eastern margin of the plateau, the low velocity layer is still found in the northern part.

Figure 6 shows the $v_{\mathrm{S}}$ distribution with individual depth in the crust and upper mantle from the receiver function analysis results (Table 1 ). In the depth range of $0-10 \mathrm{~km}, v_{\mathrm{S}}$ is lower in the Sichuan basin because the basin has huge thickness of sediments with low velocity characteristics, whereas the mountain ranges in the eastern margin of Tibetan plateau show higher velocity. In the depth ranging 10-40 km beneath the Sichuan basin, we find higher $v_{\mathrm{S}}$ in the middle and lower crust, while the eastern margin of Tibetan plateau shows lower 

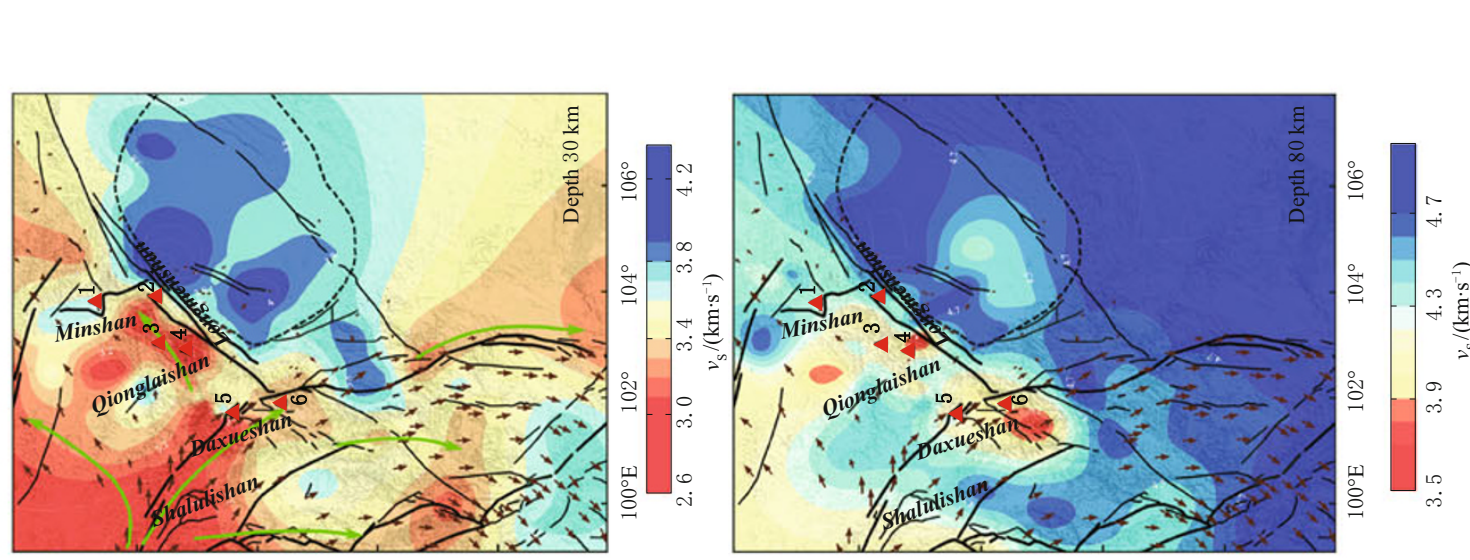

岁

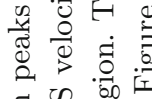

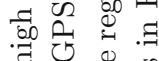

$\tau$ 당

के

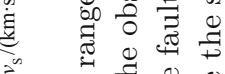

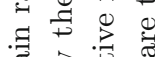

雪雚皆

范

胥

돌 है

용 ज
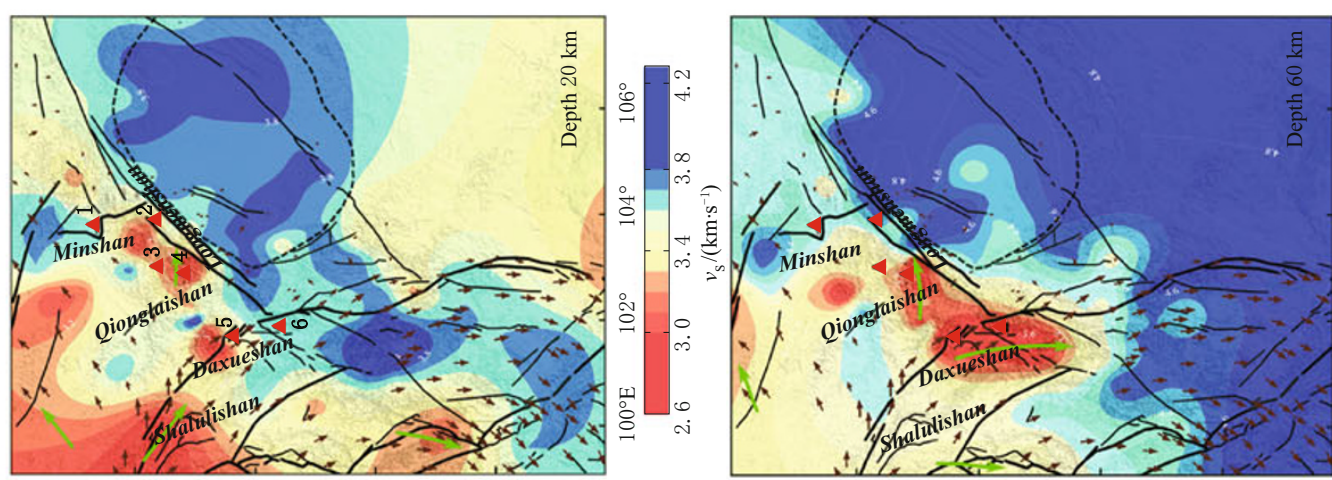

运

䊈

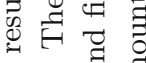

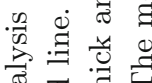

范

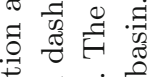

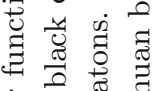

ब

字蛋

व
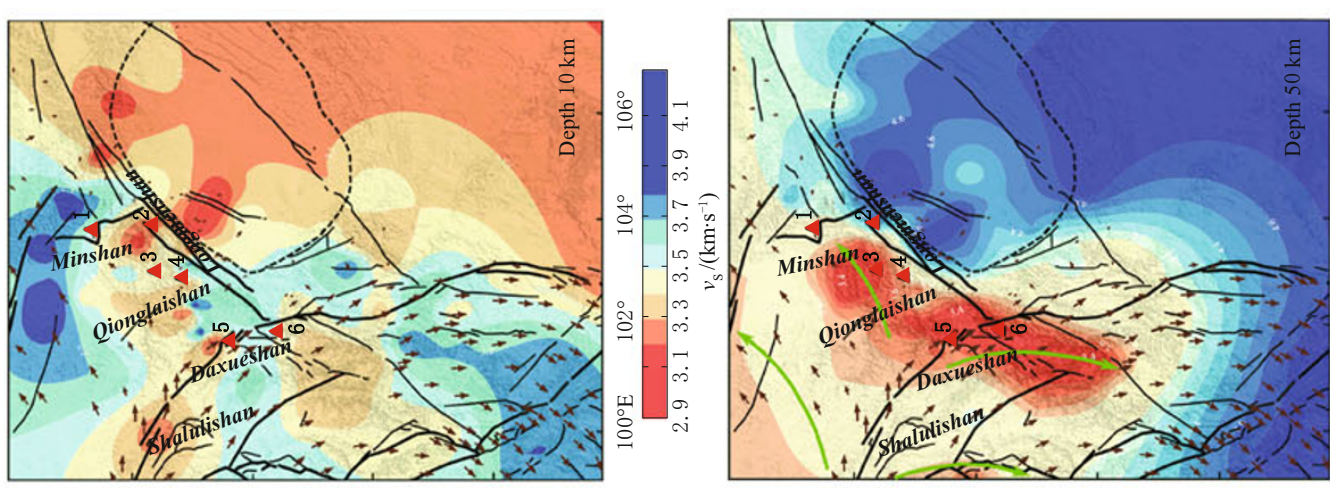

苟

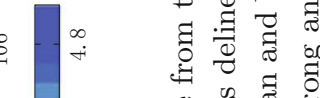

․․․ㄹ

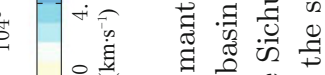

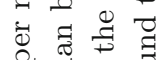

역 쿵우

च

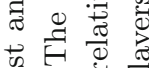

हैं है

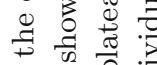

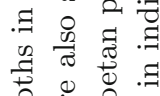
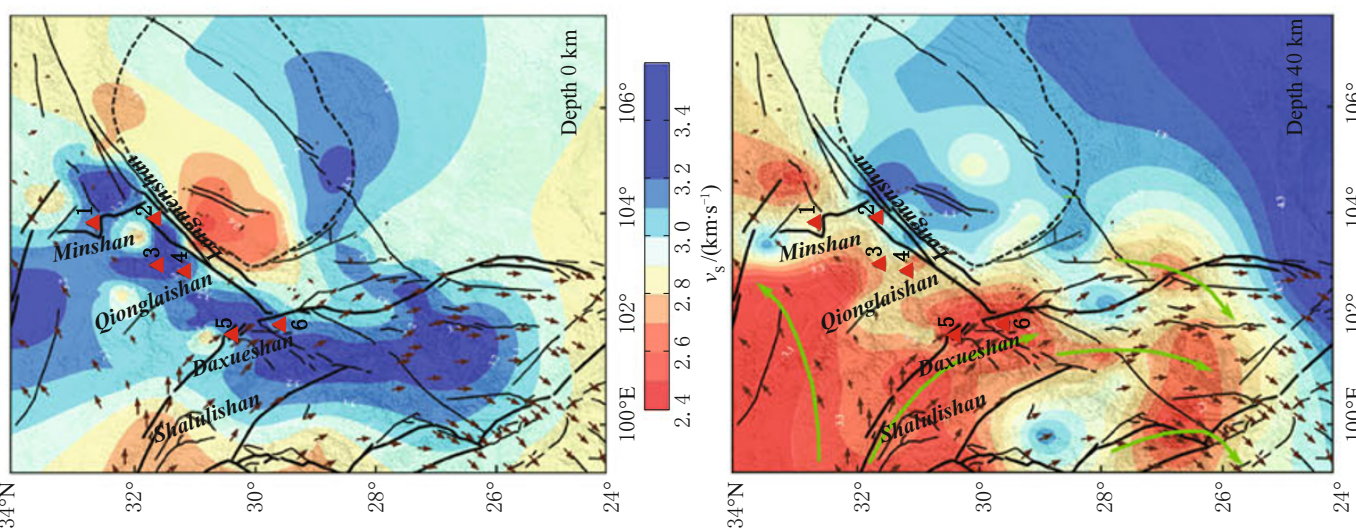

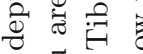

규 ᄚ

递范

क ₹

:

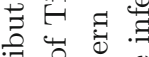

莺

इ

○ 둥 छ

范荡

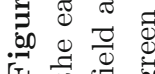


velocities. In the depth from $50 \mathrm{~km}$ to $60 \mathrm{~km}$ beneath the Sichuan basin the higher velocities are indicated in the upper mantle. However, in that depth range, the lower crust is still present beneath the eastern margin of Tibetan plateau, with characteristic lower velocities. At the depth $80 \mathrm{~km}$, both regions show the presence of upper mantle, but the velocity distributions are clearly different. In the eastern margin of Tibetan plateau the low velocity layer is still found in the northern part.

According to the distribution and pattern of low velocity zones in each layer, we can infer the presence of viscous crustal flow, which drives the crustal material around the rheologically strong Sichuan basin, shown by green arrows in Figure 6 . The direction of crustal viscous flow coincides primarily with the observed GPS velocity field around the Tibetan plateau relative to the Sichuan and Yangtze cratons.

The crustal viscous flow does not show growth in any region, and most of the flow direction is along the main active faults. The effective middle and lower crustal channel thicknesses have been estimated to be 20-40 km, namely, the crustal viscous flow is heterogeneously dispersed over the depth range of $20-60 \mathrm{~km}$. Similar viscous flow in the eastern margin of Tibetan plateau is discussed and presented in several papers (Wang et al., 2007; Zhu, 2008; Xu et al., 2009; Bai et al., 2010).

Recently, several papers have been published that investigate the crustal $v_{\mathrm{S}}$ velocity structure and deformation in eastern Tibet, using ambient noise and surface wave tomography (Yao et al., 2008; Yao and van der Hilst, 2009; Li et al., 2009; Zheng et al., 2010; Yang et al., 2012). Based on 1-2 years of continuous observations of seismic ambient noise data obtained at more than 600 stations in and around Tibet, Rayleigh wave phase velocity maps have been constructed from $10 \mathrm{~s}$ to 60 s periods. A 3-D $v_{\mathrm{S}}$ model of the crust and uppermost mantle is derived from these maps. The $3-\mathrm{D}$ model exhibits apparently inter-connected low shear velocity features across most of the Tibetan middle crust at depths between $20 \mathrm{~km}$ and $40 \mathrm{~km}$ (Yang et al., 2012). Yao et al. (2008) and Yao and van der Hilst (2009) have determined the 3-D shear wave speed variations in the crust and upper mantle in the SE Tibetan plateau, with data from 25 temporary broad-band stations and one permanent station. The results show that, in some regions prominent low velocity layers occur in the middle crust, but in others they may appear in the lower crust. In some cases the lateral transition of shear wave velocity coincides with major fault zones (Yao et al., 2008; Yao and van der Hilst, 2009).

Throughout the Alpine-Himalaya orogenic belt, continental crust deformation and thickening have resulted in active orogen. These blocks behave as rigid obstacles to ongoing deformation. In the eastern margin of the Tibetan plateau, this obstacle is the strong and rigid Sichuan basin. It has caused crustal thickening and elevated topography along the margin. This has been proposed to be the direct result of weak lower crustal material being evacuated from beneath the central Tibetan plateau (Royden et al., 1997; Clark and Royden, 2000).

The observed GPS velocity field around the eastern margin of Tibetan plateau relative to the Sichuan and Yangtze cratons (Gan et al., 2007; Wang et al., 2008) shows that most of the motion at the surface and uppermost crust is oriented parallel to the boundary of the obstacle. A concave steep region along the eastern margin of Tibetan plateau against the strong Sichuan basin has remained as an undeformed low-lying region.

There is very little convergence across the eastern margin of Tibetan plateau to the boundary adjacent to the strong Sichuan basin. The paths of crustal viscous flow are largely directed parallel to the margin, and coincide with the GPS velocity field. As the eastern margin of Tibetan plateau wraps around the obstruction of Sichuan basin, viscous crustal flow remains parallel to the boundaries of the strong region, particularly in the lower crust. The crustal flow moves around the obstruction, although in some places it has a component of motion toward the plateau margin.

\section{The moving pattern of crustal viscous fluid and its dynamics for crustal deformation}

As shown in Figure 7, the low velocity layer distribution in the middle and lower crust is irregular, with various thicknesses. Particularly, these low velocity layers act as a viscous fluid, and show different flow directions. In general, flows have moved in the horizontal direction, however, when they hit the strong Sichuan basin, the direction is changed to an up or down direction. We have modeled the middle and lower crust as a viscous fluid bounded within a fixed rigid horizontal boundary overlain by an elastic layer that is free to deform under the influence of the dynamic pressures generated. Flow within the channel is presumed to be driven by horizontal pressure gradients associated 
with topographic gradients across the eastern Tibetan plateau boundary adjacent to the Sichuan basin.

The thickness of the low velocity layer varies from 20 to $40 \mathrm{~km}$, even $50 \mathrm{~km}$. The viscosities of the low velocity layer range from $10^{17}$ to $10^{20} \mathrm{~Pa} \cdot \mathrm{s}$. The flow in the crust has been proposed to occur over length scales of tens to hundreds of kilometers and possibly over more than $1000 \mathrm{~km}$ (Clark and Royden, 2000; Cook and Royden, 2008), with flow durations on the order of $10^{6}-10^{7}$ a. Flow within the crust is driven by horizontal pressure gradients from the central Tibetan plateau, due to topographic gradients and variations in crustal thickness.

The upper part of viscous flow upwelling produces the pressure to intrude the upper crust and to uplift the mountain ranges and high peaks in the eastern margin of Tibetan plateau. In contrast, the downwelling viscous flow produces the pressure to intrude the lower crust and upper mantle to deepen the Moho discontinuity, causing the crust to thicken as shown in Figure 6.
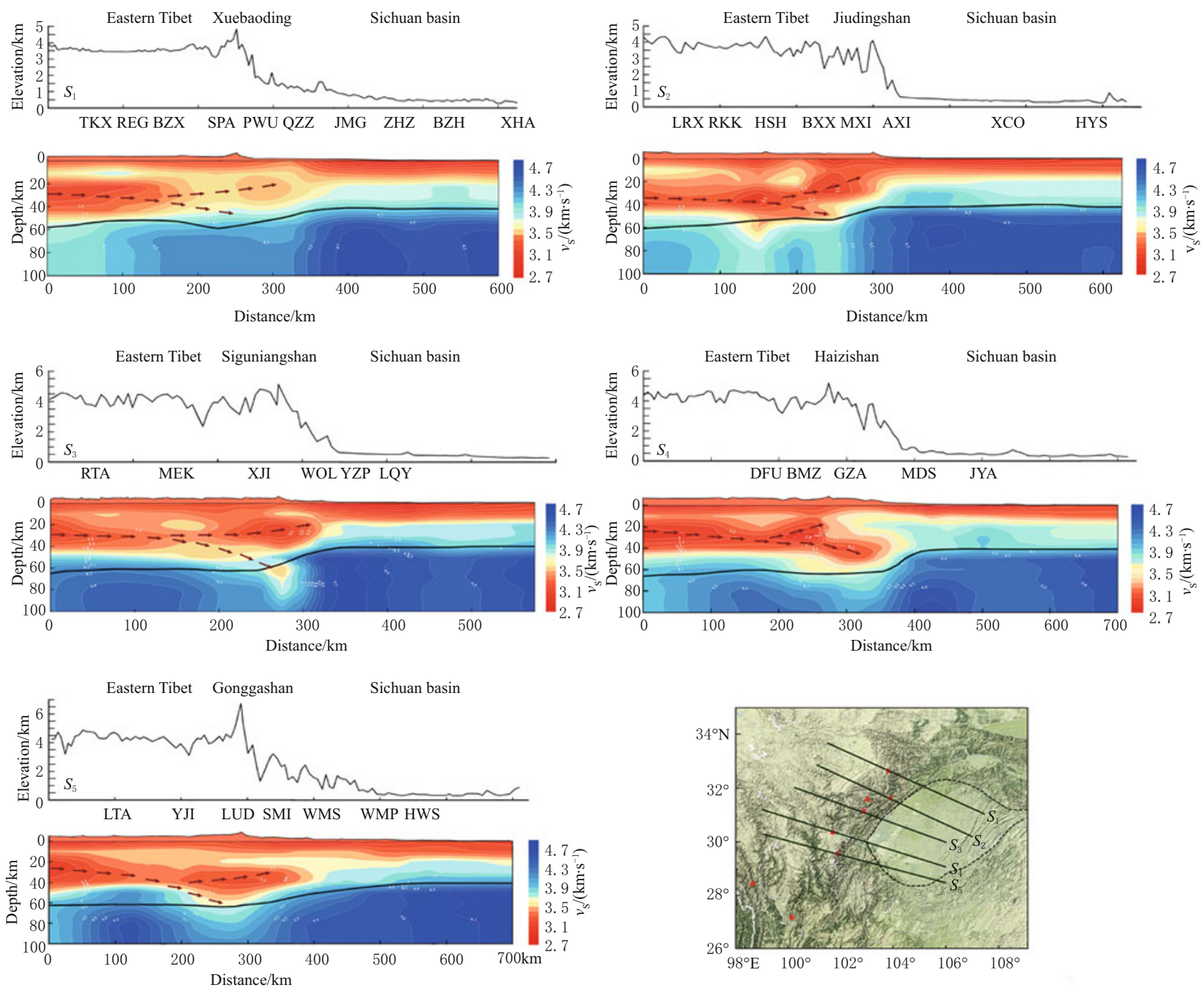

Figure 7 Comparison of the crustal structure and topography along the eastern margin of the Tibet plateau adjacent to the Sichuan basin. Five profiles of $v_{\mathrm{S}}$ velocity of the crust and upper mantle are shown. The black line in these profiles indicates the boundary. Arrows in low velocity layer indicate the flow's dominant direction. The codes for high peaks are same as in Figure 1, and the station codes shown in the profiles. Refer to Figure 1 for mountain peaks marked by red triangles. 


\section{Conclusions}

The eastern margin of Tibetan plateau, adjacent to the strong crustal Sichuan basin, is characterized by a series of extremely steep mountain ranges and high peaks with NE-trend and several subparallel NNW trend. Beneath this region there are low-velocity zones within thick crust, whereas the Sichuan basin is interpreted as a region of strong rigid crust and upper mantle. In order to improve our understanding of crustal low velocity zones, and the dynamic process of viscous fluids in the middle and lower crust, we have adopted the relatively dense network of temporary and permanent broadband seismometers to estimate the fine S-wave velocity structure in the crust and upper mantle in this region.

The crust varies in thickness of $50-66 \mathrm{~km}$ in the eastern margin of the Tibetan plateau and 40-44 km in the Sichuan basin. The gradient of the Moho discontinuity is the greatest in the boundary along the eastern margin of the Tibetan plateau toward the Sichuan basin. The same boundary morphology is characterized by a series of extremely steep mountain ranges and high peaks.

According to the distribution of low velocity zones in the middle and lower crust at each point, we can infer that the viscous crustal flow drives the crustal material around the obstacle of the strong rigid Sichuan basin. The crustal flow is not growing anywhere, and most of the flow direction is found to occur along the main active faults. The flow direction coincides with the observed GPS velocity field around the eastern margin of Tibetan plateau relative to the Sichuan basin and Yangtze craton. The effective middle and lower crustal thicknesses have been estimated to be between 20 and $40 \mathrm{~km}$, namely, the crustal viscous flow is distributed dispersedly at the depth of $20 \mathrm{~km}$ even extending heterogeneously to $60 \mathrm{~km}$. The viscosities of the flow range from $10^{17}$ to $10^{20} \mathrm{~Pa} \cdot \mathrm{s}$, and occur in the crust over length scales of hundreds of kilometers, and possibly over more than $1000 \mathrm{~km}$. Flow within the crust is driven by horizontal pressure gradients from the central Tibetan plateau due to topographic gradients and variations in crustal thickness.

When the viscous flows in the middle and lower crusts hit the obstruction of the strong rigid Sichuan basin, these flows are divided into two or more branches with different directions. The upper part of viscous flow upwells to produce enough pressure to intrude the upper crust, thereby uplifting the mountain ranges and high peaks along the eastern margin of Tibetan plateau. Whereas the lower downwelling part of viscous flow produces the pressure to intrude the lower crust and upper mantle to deepen the Moho discontinuity, causing the crust to thicken.

Acknowledgements We thank Dr. Lili Xu, Prof. Robert D van der Hilst and Prof. Z. Chen for providing us both the field data collected from their south Yunnan array studies and their $v_{\mathrm{S}}$ crustal velocity models. Thanks are also to Dr. Qiang Xu for providing the inversion codes in our velocity structure study. This research was supported by National Natural Science Foundation of China under grant Nos. 40839909, 41074062, and 40674040.

\section{References}

Ammon C, Randall G and Zandt G (1990). On the nonuniqueness of receiver function inversions. J Geophys Res 95: 15 303-15 318.

Beaumont C, Jamieson R A, Nguyen M H and Medvedev S (2004). Crustal channel flows: 1. Numerical models with applications to the tectonics of the Himalayan-Tibetan orogen. J Geophys Res 109: B06406, doi:10.1029/2003JB002809.

Brown L D, Zhao W, Nelson K D, Hauck M, Alsdorf D, Ross A, Cogan M, Clark M, Liu X and Che J (1996). Bright spots, structure, and magmatism in southern Tibet from INDEPTH seismic reflection profiling. Science 274: 1 688-1 690.

Burchfiel B C, Chen Z, Liu Y and Royden L H (1995). Tectonics of the Longmen Shan and adjacent regions, Central China. International Geology Reviews 37: 661-735.

Burchfiel B C, Royden L H, van der Hilst R D, Hager B H, Chen Z, King $\mathrm{R}$ W, Li C, Lu J, Yao $\mathrm{H}$ and Kirby E (2008). A geological and geophysical context for the Wenchuan earthquake of 12 May 2008, Sichuan, People's Republic of China. GSA Today 18: 4-11, doi:10.1130/GSATG18A.l.

Clark M K and Royden L H (2000). Topographic ooze: building the eastern margin of Tibet by lower crustal flow. Geology 28: 703-706.

Clark M K, Schoenbohm L M, Royden L H, Whipple K X, Burchfiel B C, Zhang X, Tang W, Wang E and Chen L (2004). Surface uplift, tectonics, and erosion of eastern Tibet from large-scale drainage patterns. Tectonics 23: tc1006, doi:10.1029/2002TC001402.

Clark M K, Bush J W M and Royden L H (2005). Dynamic topography produced by lower crustal flow against rheological strength heterogeneities bordering the Tibetan Plateau. Geophys J Int 162: 575-590, doi:10.1111/j.1365-246X.2005.02580.

Cook K L and Royden L H (2008). The role of crustal 
strength variations in shaping orogenic plateaus, with application to Tibet. J Geophys Res 113: B08407, doi:10.1029/2007JB005457.

Gan W, Zhang P, Shen Z K, Niu Z, Wang M, Wan Y, Zhou D and Cheng J (2007). Present-day crustal motion within the Tibetan Plateau inferred from GPS measurements. $J$ Geophys Res 112: B08416, doi:10.1029/2005JB004120.

Gray R and Pysklywec R N (2012). Geodynamic models of mature continental collision: Evolution of an orogen from lithospheric subduction to continental retreat/dekanubatuib. J Geophys Res 117: B03408, doi:10.1029/2011JB008692.

Kirby E, Whipple K X, Tang W and Chen Z (2003). Distribution of active rock uplift along the eastern margin of the Tibetan Plateau: Inferences from bedrock channel longitudinal profiles. J Geophys Res 108(B4): 2217, doi:10.1029/2001JB000861.

Langston C A (1979). Structure under Mount Rainier, Washington, inferred from teleseismic body waves. $J$ Geophys Res 84(B9): 4 749-4 762.

Li H, Su W, Wang C Y and Huang Z (2009). Ambient noise Rayleigh wave tomography in western Sichuan and eastern Tibet. Earth Planet Sci Lett 282: 201-211, doi:10.1016/j.epsl.2009.03.021.

Liu Q Y, Li Y, Chen J H, Guo B, Li S H, Wang J, Zhang X Q and Qi S H (2009). Wenchuan $M_{\mathrm{S}} 8.0$ earthquake: Preliminary study of the $\mathrm{S}$ wave velocity structure of the crust and upper mantle. Chinese J Geophys 52(2): 309-319 (in Chinese with English abstract).

Nelson K D, Zhao W J, Brown L D, Kuo J, Che J K, Liu X W, Klemperer S L, Makovsky Y, Meissner R, Mechie J, Kind R, Wenzel F, Ni J, Nabelek J, Chen L S, Tan H D, Wei W B, Jones A G, Booker J, Unsworth M, Kidd W S F, Hauck M, Alsdorf D, Ross A, Cogan M, Wu C D, Sandvol E and Edwards M (1996). Partially molten middle crust beneath southern Tibet: Synthesis of Project INDEPTH results. Science 274: 1 684-1 687.

Owens T J, Zandt G and Taylor S R (1984). Seismic evidence for an ancient rift beneath the Cumberland Plateau, Tennessee: A detailed analysis of broadband teleseismic $\mathrm{P}$ waveforms. J Geophys Res 89(B9): 7 783-7 795.

Royden L H, Burchfiel B C, King W R, Wang E, Chen Z, Shen F and Liu Y (1997). Surface deformation and lower crustal flow in eastern Tibet. Science 276: 788 790, doi:10.1126/Science.276.5313.788.
Shen F, Royden L H and Burchfiel B C (2001). Large-scale crustal deformation of the Tibetan Plateau. J Geophys Res 106(B4): 6 793-6 816.

Wang C Y, Han W B, Wu J P, Lou H and Chan W W (2007). Crustal structure beneath the eastern margin of the Tibetan Plateau and its tectonic implications. J Geophys Res 112: B07307, doi:10.1029/2005JB003873.

Wang Y Z, Wang E N, Shen Z K, Wang M, Gan W J, Qiao X J, Meng G J, Li T M, Tao W, Yang Y L, Chen J and Li P (2008). GPS-constrained inversion of present-day slip rates along major faults of the Sichuan-Yunnan region, China. Science in China (Series D) 51(9): $1267-1283$ (in Chinese with English abstract).

Xu L, Rondenay S and van der Hilst R D (2007). Structure of the crust beneath the southeastern margin of Tibetan Plateau from teleseismic receiver functions. Physic Earth Planet Inter 165: 176-193.

Yang Y, Ritzwoller M H, Zheng Y, Shen W, Levshin A $\mathrm{L}$ and Xie Z (2012). A synoptic view of the distribution and connectivity of the mid-crustal low velocity zone beneath Tibet. J Geophys Res 117: B04303, doi:10.1029/2011JB008810.

Yao H and van der Hilst R D (2009). Analysis of ambient noise energy distribution and phase velocity bias in ambient noise tomography, with application to SE Tibet. Geophys J Int 179: 1 113-1 132.

Yao H, Beghein C and van der Hilst R D (2008). Surfacewave array tomography in SE Tibet from ambient seismic noise and two-station analysis: II — Crustal and upper-mantle structure. Geophys J Int 163: 205-219, doi:10.1111/j.1365-246X.2007.03696.x.

Zheng Y, Yang Y, Ritzwoller M H, Zheng X, Xiong X and Li Z (2010). Crustal structure of the northeastern Tibetan Plateau, the Ordos block and the Sichuan basin from ambient noise tomography. Earthquake Science 23: 465-476, doi:10.1007/s11589-010-0745-3.

Zhu L P and Kanamori H (2000). Moho depth variation in southern California from teleseismic receiver functions. $J$ Geophys Res 105(B2): 2 969-2 980.

Zhu J S (2008). The Wenchuan earthquake occurrence background in deep structure and dynamics of lithosphere Journal of Chengdu University of Technology (Science \& Technology Edition) 35(4): 348-356 (in Chinese with English abstract). 